\section{CONTINUOUS PRESSURE IN ENLARGEMENT OF THE LIMBS.}

\section{To the Editor of THE LANCET.}

SIR,-In the report, contained in THE Lancet of the $3 \mathrm{rd}$ inst., of the proceedings of the Clinical Society on Friday, March 12th, it is stated that in the discussion which followed Dr. W. H. Day's able and interesting communication, "Dr. Cholmeley and Mr. Barwell expressed the opinion that the enlargement of the limb was due to excessive arterial supply, and that accordingly the proper treatment would be to apply continuous pressure to the femoral artery." You will, I hope, allow me to state that I did not express, and certainly did not wish to convey the impression that I held, any such opinion. I described a case of great enlargement of the right lower extremity, in a child which had been under my care, and which presented many points of close resemblance to Dr. Day's case, but differed from it in not showing any visible enlargement of the lymphatics, and in which I had tried, among other things, pressure of the femoral artery, but without any satisfactory or lasting result. I am, Sir, your obedient servant,

Russell-square, April 12th, 1869.

Wrultam Cholmeley.

\section{ST. GEORGE'S, SOUTHWARK.}

To the Editor of THE LANCET.

SIR,-You have in your last issue, p. 511, honoured me by noticing my intended retirement from a London vestry. The consequence is, some friends of mine have been questioning me about what they are pleased to call my hasty step. Will you allow me to give an explanation in your pages? I ask this because it may in addition serve a public purpose. For years past I have endeavoured to bring about a serviceable connexion between the medical officers of the vestry and guardians in my parish, so that no first, or at most second, case of typhoid or typhus in filthy and crowded homes should fail to be reported promptly to the sanitary authorities. With us, the first cases of these fevers occur almost uniformly among the poor in receipt of parish relief, who are attended by the Poor-law surgeon. This being the case, if five, six, seven, or eight cases of fever occur week after week successively in the same rooms, it is a public scandal. Two cases of this sort have now been brought to my notice by charitable ladies visiting in our parish. In each seven or eight cases of typhus had occurred one after another ; in one the father and mother died, leaving the children to public charity. In the last three years we have had 127 deaths from fever, and about 1000 cases. This last year we have sent 167 fever and allied cases to the Fever Hospital, 162 of which were paupers. The Act under which our medical officer of health is appointed states that he is " to take cognisance of the fact of the existence of any contagious or epidemic diseases, and to point out the most efficacious mode of checking or preventing them." But if in a population of nearly 60,000 people, closely packed as we are, he is not informed of the cases, how is he to use the powers of prevention? The guardians wish to co-operate, and to do what is best, they say; and pass very humane resolutions, requesting their medical officers to do this needful work. But they appear to shirk in ordering it, and paying for it, or declaring right out that this is, or is not, already part of the duty the medical officers under the Poorlaw have engaged to perform. The fact is, that the essence of the Poor-law system, as administered of late, has been to act upon the cheap principle of pressing very hard indeed upon individual responsibility, especially upon subordinates; but to act spasmodically under the influence of panic of public opinion, if anything unfortunate should turn up: in this last case, throwing overboard any unfortunate scapegroat; and then, the storm overpast, to drop the subject quietly until the next similar cycle. In this way no doubt the unfortunate medical officer is to be treated with us. I decline, however, to be a party to the transaction, and I decline being subjected to a vestry squabble when I think it my duty to move in such matters. How guardians can consent to incur obloquy for doing, or failing to do, in connexion with such a system of time-serving, and gross in. equality in every way, is past my comprehension. I have now proposed to our sanitary committee, and it is unanimously agreed to submit to my vestry (St. George's, Southwark) a plan of immediate report of fever cases, and a sum. mary report at every meeting of the guardians and sanitary authorities, so that no cases shall hereafter be overlooked. I have, further, explained that the reason why this "fuss" is made about fever is, because typhus is among us-almost, if not quite, the best test of overcrowding and chronic animal filthiness; and typhoid, the test of bad drainage, \&c. If my scheme is adopted, I go to the vestry and co-operate as before; if not, my duty lies outside, to visit the cases myself, and on neglect or contravention of the law as we have to administer it, to try an inquest or two in any fatal case. Because one leaves a vestry, or any other public body, it is not implied that duty is abandoned or neglected. It might possibly happen that the only way left open to a man might be to leave his place, and do his work outside. While we have such a splendid public press, this mode pro. mises success after all others fail, and no one knows this better than I do.

I am, Sir, your obedient servant,

Newington-Canseway, April, 1869. W. RENDLE.

\section{DUBLIN.}

(FROM OUR OWN CORRESPONDENT.)

Some short time since it was my melancholy duty to have to announce to the readers of THE LANceT the death of Maurice Collis, Surgeon to the Meath Hospital ; but at the time I did not consider it prudent to allude to a morement that had been originated, on the part of some of his admirers and friends, to raise a fund for his family, which had been so prematurely deprived of his exertions just at the moment that he was running into remunerative practice. The event has justified my reticence, inasmuch as his family have declined all such assistance; but his friends, determined at all hazards to evince their love for his memory and appreciation of his devoted services to the profession he adorned, have resolved to raise a subscription for the erection of a ward to his memory in the hospital he sotruly loved, in which he worked so worthily, and in the operating theatre of whieh at last he sacrificed his valuable life. The subscription list already represents a handsome sum; and I feel convinced that in his death, as in his life, he will have advanced the interests of the institution in which he took so warm an interest.

At the last meeting of the Council of the Irish Medical Association, as was expected, an address of condolence to his bereaved widow was unanimously adopted, deploring the loss of their chairman, Mr. Collis; but many of the members of the Committee were taken by surprise-a surprise deeply tinged with feelings of intense sorrow-to hear then for the first time the announcement of the death of one of the most venerated of their members, formerly on many occasions their president, and at the period of his death one of their vice-presidents, Thomas Lewis Mackesy. A provincial surgeon, practising in one of our cities of second-rate importance, Dr. Mackesy, by pure dint of energy of character, of unselfish devotion to the advocacy of the best interests of his professional brethren, of an unsullied professional and general reputation, won for himself first a seat upon the Council of the College of Surgeons, and subsequently achieved the hitherto unequalled honour of being the only provincial surgeon who ever became its president. It has been my duty, on former occasions, to bring this gentleman's name prominently before the notice of your readers as that of one who took a warm and enlightened interest in the progress of our profession and in all that affected its material prosperity. Many men may boast of the inclination to act as he did, but few are so blessed by the gifts of Providence as he was, and at the same time possessed of his noble and philanthropic views. Of commanding intellect, of untiring energy and zeal, of great self-abnegation, 